\title{
Recapitalizing mini-bus taxis for effective public transportation in South Africa: the urban rural transport connection problem
}

\author{
M. P. Sebola \\ Department of Public Administration, University of Limpopo, \\ South Africa
}

\begin{abstract}
This paper argues that the recapitalization of mini-bus taxis in South Africa as a solution to the public transport challenge is not fairly achievable as a public transport policy objective. The Taxi Recapitalization Programme (TRP) of the mini-bus taxi industry in South Africa was adopted to improve commuter safety, end violence in the industry and to professionalize the business in order to improve its economic viability. The intended benefits of the policy have thus far produced contradictory results with the resultant effects such as impossible policy implementation problems, retention of status quo of the old taxi business after policy due dates and the collapse of mini-bus taxi businesses of intended beneficiaries of the policy. The mini-bus taxi industry in South Africa was historically operated on a self-imposed specific context suitable for an environment of business operation. The environmental context (urban or rural) is very important as it determines the success of a public policy in benefiting citizens concerned. The paper further argues that had the application of the TRP been applied with the consideration of differing geographical contexts of South Africa, success could have been fairly achieved. This paper therefore conclude that the application of a one-size-fits-all approach of the TRP to all mini-bus taxi owners irrespective of consideration of environmental contexts (rural or urban) is a cause of the failure of the implementation of the programme in South Africa.

Keywords: mini-bus taxi, taxi operator, environmental contexts, urban transport, recapitalization, public transport.
\end{abstract}




\section{Introduction}

The South African government's intention to turn around the mini-bus taxi industry was meant to create an industry that will support a strong economy and consider the safety of passengers while improving the socio-economic conditions of the country (South Africa Online [1]). A major concern of the TRP is therefore to have a taxi industry that will promote safety, the country's socio-economic objectives, proper management and ending violence that use to characterize the industry's operation. This move was informed by the need to restructure the functional operations of the mini-bus taxis for a better integrated public transport system. In doing this the government used a one size fits all approach in recapitalizing the taxi industry without considering the environmental contexts of mini-bus taxi operations. This paper therefore contends that only the consideration of the environmental contexts of mini-bus taxi operation can improve the effectiveness of the implementation of the TRP. A major research question raised in this paper is that: Is the Taxi Recapitalization Programme relevant in solving both urban and rural public transport dilemma in South Africa? This paper will keep the relevance of its discussion on The Minibus taxi industry in South Africa, The Taxi Recapitalization Programme, The challenges facing the Implementation of the Taxi Recapitalization Programme and the significance of the urban rural network connection for mini-bus taxi services.

\section{The taxi recapitalization programme in South Africa}

The programme came in as an initiative of the political term of office of the then minister of Transport Mac Maharaj in 1996 after forming a National Taxi Task Team that conducted 36 public hearings nationwide (Dugard [2]). With the public hearings conducted the government intended to produce a policy that should have been informed by the opinion of the entire public and mini-bus taxi commuters in the country. Luke and Heyns [3] are of the view that public opinion is very important in developing and rolling out a programme that will be responsive to the needs of the people. This initiative (TRP); put as its priority the provision of safe, effective, affordable and accessible taxi operations nationwide based on New Taxi Vehicle (NTV) model as providers of public transport (White Paper on Transport Policy [4]; Department of Transport [5]). Sebola and Baloyi [6] revealed that the programme indeed introduced three significant aspects to the conventional taxi business in the country such as replacement of old mini-bus taxis (14 and 16 seaters by 18 and 25 seaters), issuing valid operating licenses to all qualifying taxi operators and giving an incentive of a R50,000 scrapping allowance. From a safety perspective the initiative was very possible; however there are other significant aspects that seem to have been overlooked such as affordability by taxi operators and the feasibility of the implementation of the programme to suit both the needs of taxi operators and the government. The rolling out of the programme included practically ambitious objectives such as adherence to operating licences, use of roadworthy vehicles on 
South African public roads and the use of licenced drivers. This included the certification of approved vehicles to ferry the public such as Toyota Quantum, Nissan Interstar, Fiat Duncao, Mercedes Benz 380CDI and Peugeot Boxer HDI with strict safety measures such as safety belts, roll over protection and type $2 \mathrm{~A}$ braking system (Ministry of Transport [7]). From the perspective of both the economic conditions of the country and corruptive law enforcement problems it becomes highly impossible to expect the achievement in rolling out this programme successfully in South Africa. The National Treasury in South Africa [8] challenged the ambition of the TRP on putting more efforts on safety than law enforcement problems encountered on South African public roads. The replacement of old fleet by the new fleet could be a challenging reality to taxi operators who would not be in a position to manage the affordability of the costs of new vehicles required by the programme.

\section{The South African mini-bus taxi industry}

The South African taxi industry comprises of two forms; namely metered taxis and mini-bus taxis. The mini-bus taxi industry is the most common form of public transport contributing to the formal economy of the country. It is a form of public transport practice with designated parking (taxi ranks) in cities and rural areas of the country. They are believed to be the fastest and common public transport used by South Africans. They transport between 68 and $70 \%$ of South African commuters on daily basis (Walters [9]). Because they don't have designated stops in towns, cities and rural areas they stop anywhere anytime the driver and the passenger so requires. That gave them an advantage against other forms of public transport such as busses and railways that have designated stops which often might not be of an advantage to the commuters. National Treasury of South Africa [8] indicated that mini-bus taxi industry in South Africa accounts for $63 \%$ of public transport users to work, school and other purposes. The minibus taxis are believed to be the fastest in commuting employees, school learners and other members of the public to their destination other than other modes of road transportation. The alternative modes of road transportation such as busses are to the advantage to commuters only as far as the pricing is concerned. Minibus taxis charges slightly higher than busses in price to the destination. It should also be noted (Pillay [10]) that public transportation in South Africa affects both the rich and the poor when considering the high rising costs of fuel and high traffic congestions in cities which forces private car owners to resort to public transportation.

Historically the industry is infamous of violence confrontations of rival business competitors and exclusion from the formal economy (Barret [11], Van Schalkwyk [12]). The industry absorbs about $95 \%$ of workers as taxi drivers (mostly men) who provide public transport in the country with a very small fraction of $2 \%$ as women who provides administrative work (International Labour Organization [13]). Considering that most transport studies never looked at the gendered perspectives of the mini-bus taxi industry (Khosa [14]) there are few women who for unknown economic reasons are employed as drivers. Of 
importance about the mini-bus taxi industry in South Africa is that it has a three special unusual character of practice and use. Firstly, the industry is male dominated with an overall total employees being male drivers (often very rude and violent in character, fast drivers with little respect for traffic laws). Secondly, the entire passengers are Africans (South African whites are rarely commuting in such public transport, except white tourists exploring interaction with locals Africans for specific reasons) and thirdly that they are capable of resisting the formalization of their business at all costs (they survived that during the apartheid era and are still continuing). The government's intention to formalize the mini-bus taxi industry such that it should be able to generate revenue and pay tax to government is still not possible since the TRP is only being able to introduce little changes which are not sustainable to the industry.

Unlike other forms of public transport systems in the country such as rail and busses which takes over R4.5 billion of government subsidy annually, the taxi industry receives no subsidy at all (Geldenhuys [15]), this could partly be attributed to their inability to be formalized as a business. This happens beside the acknowledgement that the mini-bus taxi industry contributes a great fraction of percentage in job creation. The government's new method of subsidy which is a once off R50,000 scrapping allowance for a replacement of old taxi vehicle (a deposit for a new one) is not a solution to government's lack of support for the industry concerned. The once off R50,000 scrapping allowance is not sufficient to afford the costs of new vehicles needless to say that the deposit of a new minibus taxi is over R60,000 (Sebola and Baloyi [6]). Considering the economic contexts of mini-bus taxi owners in South Africa the R10,000 shortfall of deposit is but a major problem of concern that cannot be afforded by all taxi operators. The effect of the inability of those taxi operators that may not afford the costs of new vehicles specified for public transportation may have employment effect on taxi drivers who will lose their employment immediately their employers are out of business. It has been argued that while many taxi operators may have problems of affording minimum monthly instalments of their new vehicles, the maintenance costs of new vehicles which requires technical expertise for service may pose another problem of affordability by taxi operators. That will ultimately result in those mini-bus taxis not being reliable in terms of use while posing a threat of safety risk to commuters.

Despite the concern about the TRP being on safety of commuters; the minibus taxi industry continues to be responsible for many motor car accidents (Nandipha [16], Sebola and Baloyi [6], Baloyi [17]). Additionally, while it was anticipated that by the year 2005 all old mini-bus taxis should be out of the South African public roads as planned, such dream have not been achieved to date. The mini-bus taxi operators are still not able to afford the costs of new mini-bus taxi vehicles. Such may mean that the rolling out of the programme has not been able to achieve much for either the government or the mini-bus taxi industry in the country. Taxi operators currently in the business have the opportunity to complain about the hardship of maintaining and affording the monthly instalments of new mini-bus taxi vehicles as well as competing for business with other operators. There is an increased opportunity for taxi drivers who by virtue 
of serving under a particular taxi association for five years are promoted to taxi operators. Depending on whether the promoted taxi driver have cash to buy a vehicle or not the opportunity for mini-bus taxi ownership is possible; most of such taxi drivers may if unable to buy a mini-bus taxi approach a partner with money in order to join the industry as a taxi operator - operating with a silent business partner. This kind of business opportunities complicates the competition within the industry by increasing more business ownership in the mini-bus taxi industry while reducing the profit margins of those that existed in the taxi industry market before.

\section{The urban rural network public transport problem}

The South African roads are said to be better constructed and provided as compared to those in other countries in Africa. This however does not imply that the roads are sufficient to provide for all the requirements of public and private transport in the country. Roads are a major determinant of the safety of passengers for both public transport users and the private motorists. Like all other developing countries, South Africa also has the culture of disparity in developing roads meant for either urban or rural contexts. Mamabolo [18] highlighted that as at the year 2011, estimates were that $79 \%$ of South African roads were gravel with only $21 \%$ of them been paved. The South African aspiring transport entrepreneurs in urban areas have an advantage of access to quality roads and other facilities that will promote and sustain their transport business ventures. Contrary to that advantage; rural communities in South Africa lack access to quality road networks and therefore limiting their opportunity in playing an active role in transport business ventures. It is indeed quality road infrastructure that ensures the durability of and safety of public transport used in a particular area of the country. The hypothetical assumption in this regard is that taxi operators in urban areas are likely to exist longer through the TRP than rural taxi operators whose quality and durability of their mini-bus taxis will be affected by the poor road conditions. The poor conditions of such mini-bus taxis will have adverse consequences such as insufficient safety of commuters and maintenance costs that will ultimately makes it impossible for taxi operators to cope with their monthly payments. Table 1 below shows the South African Road Network as in 2010.

Table 1: South Africa Road Network (2010).

\begin{tabular}{|l|l|l|l|}
\hline \multirow{2}{*}{ Roads Authority } & \multicolumn{2}{|c|}{ Types of road } & \multirow{2}{*}{ Total } \\
\cline { 2 - 3 } & Paved $(\mathrm{km})$ & Gravel Roads & 16,170 \\
\hline National Roads & 16,170 & - & 184,816 \\
\hline Provincial Roads & 48,176 & 136,640 & 405,992 \\
\hline Municipal Roads & 89,373 & 316,619 & 140,000 \\
\hline Unproclaimed Rural Roads & - & 140,000 & $\mathbf{7 4 6 , 9 7 8}$ \\
\hline Total & $\mathbf{1 5 3 , 7 1 9}$ & $\mathbf{5 9 3 , 2 5 9}$ & $\mathbf{2}$ \\
\hline
\end{tabular}


However the table above show the status of road networks three years ago, but the picture drawn from this imply that road infrastructure development in the country still lacks behind with more gravel roads at the municipal and the provincial sphere. The table shows a large number of municipal roads that are not tarred followed by provincial roads and also a substantial number of unproclaimed rural roads that are not tarred. Given the status of roads conditions in South Africa as depicted by Table 1, it is indeed very risky to use a one-sizefits-all approach in applying the TRP because the entrepreneurs in this programme are likely to be affected differently, with those in urban areas of the country facing less business risk than those in the rural areas. The National Treasury of South Africa [8], showed that the South African road network comprises of $606,978 \mathrm{~km}$ of proclaimed national, provincial and municipal roads with $140,000 \mathrm{~km}$ of unproclaimed rural roads. The unproclaimed rural roads are the worst in terms of care and maintenance as compared to proclaimed gravel rural roads at provincial and municipal roads. Therefore the urban rural road network connection is incompatible and putting the taxi business very risky for rural entrepreneurs.

Thus far the operations of the mini-bus taxis follow a particular pattern to separate an urban mini-bus taxi business from a rural one. The urban mini-bus taxi operators uses rural mini-bus taxi's as a connect transport for their clients for delivery to their final rural destination. Normally, the rural commuters are ferried through local mini-bus taxis (mostly not in good roadworthy conditions) to a connecting mini-bus taxi rank (a drop off closer to a tarred road). There is a clear distinction between long distance mini-bus taxis and local mini-bus taxis which are not even similar in terms of quality and safety features. Thus far the challenge of recapitalizing the mini-bus taxis in South Africa received favourable compliance from the urban mini-bus taxi operators than the rural taxi operators, therefore limiting the achievement of the programmes objective of providing safe, affordable and reliable public transport system.

\section{Challenges of effective roll out of the Taxi Recapitalization Programme (TRP)}

It is still difficult to date to conclude that the TRP have improved the status of the mini-bus taxi industry as encapsulated. It is known in public policy environment that policies have indeed unintended consequences in which the rolling out of programme become impossible. For purposes of this paper the following are identified as challenges of the programme but not limited to; covert political objectives, inadequate environmental scanning, the costs implications and a complicated public transport system.

\subsection{Covert political objectives}

The industry is said to have originated from a loophole of the Road Transportation Act of 1977 which then failed to define this category of car (minibus) therefore leaving it to its own definition by taxi operators (Barret [11]; Van 
Schalkwyk [12]), in which it did not fit the definition of a car(less than eight passengers), Sedan taxi (four plus one) or a bus (more than eight passengers). An attempt to regulate and deregulate the industry by both the former apartheid regime and post -apartheid could only confirm one thing; that this industry is the fastest growing informal economy in the country and cannot be regulated. Unlike the apartheid government which failed to regulate it, the current government would like to reduce its influence in the public transport than transforming its services for better. It is assumed that the current mini-bus taxis are estimated between 120,000 and 140,000 with the majority operating in urban areas (Walters [9]), while on other hand the TRP aims to reduce the total number of mini-bus in the country to 85,000 (Walters [19]). The TRP is a well-articulated political move intended to reduce the flow of traffic in urban areas caused by mini-bus taxi businesses. This political solution is not equally shared by taxi operators and beneficiaries of mini-bus taxi businesses. Additionally this kind of political solution to a problem has adverse consequences that if complied to; it affects negatively both the mini-bus employees and employers. Hence a good number of compliance to the TRP was accepted by taxi operators from the urban than those from the rural areas for reason that rural compliance will compromise the ability of rural mini-bus taxi operators to afford the costs because of poor road conditions. Moreover, this politics could not function well because the mini-bus taxis are an easy to access as public transport service than busses and railways with designated stations that are far from the commuters. The problem with covert politics is that when objectives are not met, governments have little alternatives and therefore retain the status quo. The mini-bus taxi industry is a challenge as a competitor to other formal public transport systems and regulating it is problematic because of its unique nature and economic considerations for people surviving on it.

\subsection{Inadequate environmental scanning}

From the onset this business was not attended by the government with the interest to transform it to an effective institution other than the intent to limit its operations. It has been argued several times that the industry is responsible for many accidents annually (Mmadi [20], Lomme [21]) in which busses are considered to be safer mode of transport that can reduce accidents if considered for use by the public. At the same tone it is acknowledged that the industry is responsible for an employment record of about 200,000 people. While safety seems to have been a major concern of transforming the mini-bus taxi industry, the little attention paid to other environmental factors such as employment capacity of the industry, law enforcement issues and contexts of whether most of this problems are rural or urban in setting is failing the programme. Handling the mini-bus taxi industry as if it is an urban public transport problem than rural is problematic. Mini-bus taxi operations whether urban or rural serve as connecting points of each other's business and can therefore not be handled outside each other's context. A consideration of all environmental variables that affects this kind of public transport industry is important. 


\subsection{Cost implications}

When the programme was approved by the cabinet in 1999 about 97,000 minibus taxis were estimated for recapitalization (Van Ryneveld [22]) then with the assumption that mini-bus taxis were estimated at 125,200. This was to be achieved firstly with a total budget of R4.4 billion estimated to assist taxi operators to replace their ageing and unroadworthy mini-bus taxis by designated approved vehicles by the Department of Transport (Walters [9]). The budget was however later revised to R7.7 billion in 2004 after some financial and operation concerns were raised (Van Schalkwyk [12]). As at May (2007) already R2.13 billion was paid in compensation with only 42000 mini-bus taxis being scrapped (Walters [19]). Costs implications in this instance are not only in financial terms but also in terms of time spend by government trying to find solution for this matter. The rolling out of the programme is seemingly very slow and continues to be slow even after the due dates. The government and the taxi associations spend most of their time not agreeing about how to assist each other on the problem. The government sees violence, insecurity of passengers and unroadworthy vehicle as a problem requiring total eradication (Van Schalkwyk [12]), while the taxi associations' view such as normal problems that does not require an approach currently followed by the government. It is known however that the government does not have much resource that can deal with the problem to the end. Additionally as this problem persists unresolved, there are new entrants into the market using the vehicles that are not designated by government for public commuting. As much as there is no a clear agreement between the government and the taxi associations, the associations continue admitting new members and the new permits continues because of corruption in the public service. Therefore the intention to reduce the mini-bus taxis to 85000 remain a wishful dream.

\subsection{A complicated public transport system}

Unlike other forms of public road transport in South Africa, mini-bus taxis are a unique system of public transport that rarely complies with the law. The employment system in the industry is practically self-regulatory. There are no formal contracts between the employer and the employee and therefore termination of employment can be within a day or more. Employees are paid in wages and in different forms. The common one is that a driver is expected to give to the owner a particular agreed percentage of daily takings (International Labour Organization [13]; Barret [11]). Thus far unions are not able to succeed in recruiting members from the mini-bus taxi industry. Wages are lower and justified by employers because unlike other public transport system where owners' investment could be fairly secured, mini-bus taxis drop off passengers anytime anywhere and pick up new ones and therefore keeping track of the actual passengers that were commuted in a mini-bus taxi per day is not possible. Some bus companies have an inspectorate division to check on loyalty of their drivers by without announcement stopping the bus to check for those without tickets. But the mini-bus taxi industry is such a complicated business that the 
drivers can pocket the owners' money without being noticed. Thus far even the transport trade unions still find it difficult to accommodate taxi drivers as their members. Not only are labour issues its limitations, there are also complicated issues such as ownership of mini-busses which include a lot of silent partners who cannot talk in the open but rule from the shade in this dilemma. The business is also corrupt to the extent that the statistics given of ownership of mini-bus in the country may only refer to those that are legally registered by the Department of transport other than those seen on the road. There is a substantial number of stolen mini-bus taxis that commute on daily basis and registered by associations and not in government registry. Often the practice in the Department of Transport is that taxi operators were required to convert their permits to operating licences in which instance a person with ten mini-bus taxis could be registered as having one mini-bus taxi therefore the remaining operating taxis remain not officially registered.

\subsection{Complicated subsidy model}

The taxi operators in South Africa unlike other forms of public road transport in the country are not subsidized. The Department of Road and Transport is also struggling to find a suitable model to fund mini-bus taxi industry. This industry is unique because a person can own one or more mini-bus taxis and owners have no sustainable funds to sustain the business. The business itself is difficult to formalize but only the activities of its association can be successfully formalized. Busses are easily subsidized because of their status as formal organizations with clear line of ownership and operations.

\section{Is the urban rural context a solution to the implementation of the Taxi Recapitalization Programme?}

Even more than fifteen years after the approval of the TRP by the cabinet of South Africa the achievement of its objectives remains unnoticed. Sebola and Baloyi [6] recommended that the programme is likely to succeed if the scrapping fee is pushed up to at least R100,000 to accommodate all taxi operators to afford deposit for a new vehicle or to provide a lucrative deal to buy operators out of the business. That alone cannot be a solution to the problem facing the industry. From this perspective it could be argued that the one-size-fits-all approach is a problem that rendered the TRP unimplementable. The programme is engulfed into a multivariate of environmental problems which ranges from road networks, complications of the business itself from both the economics and political perspectives of government as well as lack of verifiable or reliable statistics of the business itself. The government has thus far focused on safety and economic issues of mini-bus taxi industry with less consideration of the beneficiaries of the industry, but rather on own benefit through tax and to delimit the influence of the mini-bus taxi industry as a public transport mode. Mini-bus taxis clearly articulated that as the most competitive public transport choice that compete the bus companies which are legal tax payers. The largest percentage $(65 \%)$ of 
commuters in the country chooses mini-bus taxis because they are fast, accessible and convenient to use (Walters [9]) than other transport modes. The underlying political issue on this matter is that other modes of road public transport are disadvantaged by this sector which does not pay tax to government. Thus far the government regard safety of passengers as a main issue for transformation of the industry, therefore introducing a programme that meant to reduce the industry without providing a reasonable alternative to the operators, and though an alternative is provided through the opportunities in the Bus Rapid Transport (BRT) through tendering; that is not guaranteed and to a particular extent other operators would not qualify. If commuter safety and road accidents are an issue, such issues could be geographical in the sense that in urban areas where competition of road use is high the likelihood of accidents are high. In rural areas roads are not in a good condition and therefore over speeding is impossible and road accidents are lesser. The contexts of this industry are very important if the programme is to be rolled out successfully or else the status quo remains the same. It should be known however that the TRP cannot be feasible to be applied in rural areas because the poor road conditions will not secure the durability of vehicles bought on instalment. Even in the urban areas many that opted for recapping their mini-busses for new ones are struggling to finance them and therefore they are on their exit mode from the business. There is in actual fact an urban rural connection problem in the sense that mini-bus taxis are feeders of rural taxis. They are both operating in a different space. The use of a one-size-fits-all approach complicates their relation of being feeders of each other therefore creating a likelihood of competition and violence.

\section{Conclusion}

This paper concludes that if the programme is meant to benefit the taxi operators the best way is to look at all multivariate problems associated with the industry. But if the intention is to reduce the influence of the industry then applicable political solutions could be taken at parliamentary level. But that also is not an easy road because the industry has grown so big that it wields too much power that in most cases the government has bowed down to. It is indeed a competitive public transport industry which is unique and the likelihood to have it formalized is very slim.

\section{References}

[1] South Africa online. Transport. www.southafrica.co.za/about-southafrica/transport.

[2] Dugard, J., From low intensity war to mafia: Taxi violence in South Africa (1987-2000). Violence and transition series, 4, pp. 1-52, 2001.

[3] Luke, R \& G. Heyns., Public transport policy and performance: The results of a South African opinion poll. Journal of transport and supply chain management, 7 (1), pp. 1-8, 2013.

[4] White Paper on National Transport Policy (RSA). Government printer: Pretoria, pp. 6-8, 1996. 
[5] Department of Transport., Moving South Africa: The Action Agenda. A twenty-year Strategic framework for transport in South Africa. Government printer: Pretoria, pp. 1-88, 1999.

[6] Sebola, M \& M. Baloyi., The implementation of Taxi Recapitalization in South Africa: Evaluating the future prospects of taxi operators and policy choices, Global Business technology association: New York, pp. 925-931, 2012.

[7] Ministry of Transport (RSA)., Address by the Minister of Transport Jeff Radebe. Government printer: Pretoria, pp. 1-6, 2007.

[8] National Treasury (RSA), Roads and public transportation. Government printer: Pretoria, pp. 129-140, 2009.

[9] Walters, J., Overview of public transport in South Africa. University of Johannesburg: Johannesburg, pp. 18-24, 2001.

[10] Pillay, K., The South African public transportation professional, Document transformation technologies: Pretoria, pp. 1-8, 2001.

[11] Barret, J., Organizing in the informal economy: A case study of the minibus taxi industry in South Africa, International Labour Office: Geneva, pp. 1-59, 2003.

[12] Van Schalkwyk, D., Institutional statism: An overview of the formulation of taxi recapitalization policy. Koers, 73 (4), 771-791, 2008.

[13] International Labour Organization., Organizing in the taxi industry: The South African experience, International Labour Organization: Geneva, pp. 1-32, 2003.

[14] Khosa, M., Sisters on slippery wheels: Women taxi drivers in South Africa. Transformation, 33, pp. 18-33, 1997.

[15] Geldenhuys, B., Facilities for a mini-bus taxi rapid system in Tshwane. Unpublished Masters Dissertation, Tshwane University of Technology: Pretoria, pp. 1-56, 2008.

[16] Nandipha, K., Taxi Recapitalization a mission impossible, University of the Free State: Bloemfontein, pp. 27, 2006.

[17] Baloyi, M.M., The taxi recapitalization policy: Is it a hollow dream? Journal of Public Administration, 48(2), pp. 342-352, 2013.

[18] Mamabolo, M.A., Implementation of road infrastructure projects in rural areas of South Africa: A case of Polokwane municipality in Capricorn district. University of Limpopo: Sovenga, pp. 22-37, 2013.

[19] Walters, J., Overview of public policy developments in South Africa. Research in transportation economics, 39, pp. 34-45, 2013.

[20] Mmadi, M., Taxi driver's conditions: More work, what social life? South Africa Labour Bulletin, 35(4), pp. 11-12, 2011.

[21] Lomme, R., Should South African mini-bus taxis be scrapped? Formalizing informal urban transport in a developing country. Proceedings of the CODATU XIII Conference: Ho Chi Minh City, pp. 516.

[22] Van Ryneveld, P., 15 Year Review of public transport in South Africa with emphasis on metropolitan areas. Hunter van Ryneveld (PTY) Limited: Pretoria, pp. 1-65, 2008. 